\title{
Training Labor: A Necessary Reconstruction Policy
}

\author{
By C. T. Clayton
}

THE prime object of reconstruction must be the maintenance of the present relative wage scales, now perhaps the highest American workmen have ever known. Unless the reconstruction policy makes a deliberate point of sustaining such scales and adopts sound methods for their support, there will inevitably be a sag in the wage scales in advance of any diminution in the market price of commodities - and consequently a narrowing of the margin between accustomed living costs and the income of the wageearner. This margin, even in the face of recent general reductions resulting from the elimination of overtime and Sunday work, is better than wage-earners usually have enjoyed. If this margin, which gives to wage-earners some opportunity for saving for comforts, and for physical and mental self-improvement, is a just share of the value their labor has created, equity demands its retention. Even if it be contended that this margin, which recent abnormal conditions have established, is an abnormal result not entitled to protection, abundant considerations of policy and expedience suggest its continuance.

But if that margin, which is the ratio of the wage-earner's income to his living costs, is abnormal, it cannot be sustained by mere resolutions no matter how clearly general public considerations support those resolutions. Economic pressure of competition will soon nibble it off unless some other equally powerful economic force can be mobilized in its favor. There is only one such force: the relative production of the individual worker. To sustain present relative wage scales and to meet international competition, then, we must increase our per capita production of commodities sufficiently to offset competitive pressure.

\section{Post-War Labor Placement on the Basis of Acquired Skill}

Wherever possible, workers who are released from war employments should be directed to peace-time occupations in which the skill acquired in the course of their war work may be effectively 
utilized. This seems almost too obvious to mention, but its application is not simple. Peace-time manufacturing establishments dot the whole land. Seventy-five per cent of all war contracts are said to have been awarded within four states. War contractors drew their labor forces from all directions, and neither the worker, when released, nor the peace-time employer seeking workers, will be able to establish connection unless each can learn of the supply and demand for labor of various kinds.

Industries apparently quite dissimilar employ much labor of like or similar occupation. The building of ships requires more than a hundred different kinds of skilled labor; but over 60 per cent of these are found in other industries also, and many are common to several industries. Among the remaining 40 per cent of occupations peculiar to shipbuilding are found many quite similar to those used in other industries. Carpenters, cabinet-makers, joiners, or pattern-makers can all readily take up airplane repair and replacement work as their occupations are sufficiently similar. A long list of metal-working occupations includes specialists on similar machines drilled upon processes which with comparatively little added training are almost interchangeable industrially. The utilization of occupational similarities, by an analysis of the industries, offers a very practical means of facilitating the readjustment of labor due to the cessation of war manufacturing and the revival of peace-time industries. This utilization is comparatively simple. The government has the machinery at hand ready to be set in motion. All that is necessary is to inform employers how to use existing facilities. The Department of Labor has two bureaus, each possessing some knowledge adapted to the need. Through the local community board system and its clearing reports, the employment service can find and transfer labor as it is released. It can also ascertain and report the occupations of the people that are being released. The training service of the Department of Labor maintains a staff of experts in offices scattered throughout the industrial territory who are able to suggest to manufacturers the kinds of labor among those being released which, with the least training, will be found adapted to their special needs. Virtually, these experts are able at command to write a labor-supply prescription which the manufacturer may 
present to the employment service to be filled. By this combination, using expert information possessed by the training service and the very ample facilities of the U. S. Employment Service, with the least waste of time and expense, all the available skill and experience of released labor can be saved.

For several months the Bureau of Labor Statistics in the Department of Labor, acting at the request of the employment service, has been preparing a classification of occupations-to provide a ground of common understanding between those seeking employes, and workers seeking employment-which is based upon the duties required in the several occupations. This work is now well advanced and numbers of industries have been quite well analyzed into their various occupations.

As a result of the experience of the Adjutant General's Office of the War Department in developing an analysis of trades and occupations, and basing upon that analysis a series of trade tests which were very effectively used to ascertain the extent of trade experience possessed by men drafted into the army, a series of trade test handbooks covering various industries is projected by the employment service. So far as this work has gone, the results are available to aid manufacturers and workers seeking a knowledge of the needs of employer and the qualifications of employes. Both the occupational classification and the trade tests are vastly more valuable in the hands of experts; it is therefore suggested that manufacturers may well utilize the training experts as advisors regarding the prescription which they should present to the employment service.

\section{Training in Relation to Labor Efficiency}

Every manufacturer possessing a vestibule training school has a most complete instrument for laboratory examination and analysis of the qualifications of newly employed workers. For such testing, nothing better than a vestibule school could be devised where the point to be determined is, "What is the mental tendency and to what extent do the qualifications of this new aspirant for employment go?" Of course, not all applicants may be tested in this way as the facilities of the school, like the facilities of any laboratory, are limited.

A prime cause of labor turnover-one of the greatest menaces 
to the maintenance of wage levels, both absolute and relativeis in the failure of our manufacturers to secure a full measure of productive efficiency. A recent analysis of the causes of discharge in a large establishment showed that but 10 per cent were disposed of on grounds of slacking; the other 90 per cent were discharged for reasons in most cases due primarily to failures in management. A similar analysis of the reasons for quitting given by men leaving employment, checked against conditions in the plant, disposed of 90 per cent of the quittances as likewise due to failures in management.

Six reasons may be assigned for inefficiency in production, namely, (1) power failures, (2) equipment and repair failures and limitations, (3) lack of instructions, (4) lack of training, (5) failure to supply material, (6) personal slacking. A chart recently prepared, analyzing the individual output of twenty-six men employed in one factory department, showed that in two weeks the average output of the men ran under 35 per cent of what they should have readily produced. The majority of the men turned out pretty nearly the same amount every day; and their output usually ranged in the neighborhood of three hours' value for nine hours' work. Inquiry into this very low efficiency established (1) that this was as good a department as the factory could show, (2) that the factory had a reputation for efficiency, and (3) that substantially every one of the six reasons given entered into the low result, but the sixth reason was almost a negligible consideration. The real difficulties lay in failure to supply material when and as needed, in bad organization of equipment, in recurrent failures of power and chiefly in lack of training. It is reported that a large arsenal found itself able to employ its machinery during working hours but 55 per cent of the running time, on the average. Many private establishments would not show up so well as that.

It would seem that the advocates of higher efficiency should turn their attention away from attempts to speed up those workers who already are producing reasonably well and consider the idle machines and the idle men. If the average workman, whose output is about one-third of what it could be, is given better equipment, material when he is ready for it, instructions as to what should be done with that material, and training so that he 
can execute what he is told to do, that average man will not need to be pushed at all. Neither bonuses nor other incentives are really an essential to the case. The pride of the average man in his craftsmanship and his willingness and ambition to do his share is all the incentive that is necessary. It is not unreasonable to assert that attention to these elements of production could double the individual output of the American workman.

Nor does this express all of the advantages such an analysis might suggest. All industrial workers are entitled to training. Both the employer and the worker need it-the employer because failure to have training is one of the causes of inefficiency. If the employer is to sell in the market, meeting competition both at home and abroad, he must have a larger output and a higher efficiency. He cannot get this unless his people are trained "to the nails." On the other hand the employe is entitled to and wants to have the best possible training. Such training should have a broad outlook-not be narrowed to mere repetition of monotonous and socially inefficacious movements. Both employer and worker are entitled to assistance from the government in obtaining this training,- a matter requiring access to sources of information and the gathering of educational material in a manner and to an extent beyond the reasonable powers of private organizations.

\section{Industrial Education a National Need}

Training is nearly allied to industrial education but does not quite compass its breadth. The Federal Board for Vocational Education is responsible for assisting industrial education of the vocational type. Its method of operation is through the reimbursement of state boards of education for one-half the sums they expend for the salaries of teachers in vocational schools. The board has no direct connection with manufacturers or with vestibule schools as such. It can reach the vestibule school only when the State Board of Education takes over that school as part of the public school system.

The Department of Labor's training service is concerned with industrial training as carried out by manufacturers at their own expense, for the purpose of making their labor efficient. It advises the manufacturers; it prepares for them plans for training; 
it assists them in the carrying out of those plans. In a way, the work of the Department of Labor is a kindergarten service for the higher industrial education being promoted by the Federal Board for Vocational Education. It promotes organization of vestibule departments in industrial establishments, the ultimate development of which may be and very frequently will be a better appreciation of the benefits of comprehensive industrial education. In the thirty-eight states where there are compensation laws, training is of special importance because it has been found that a great majority of injuries to working people are caused by ignorance. Most accidents happen within the first few hours of employment, and these accidents may be greatly reduced by previous training. Both quality and quantity of output is greatly increased in plants where the employes are regularly trained, because during the course of training accuracy is instilled.

The training room of a large airplane factory a few days ago was called upon to aid one of the factory departments which had fallen into difficulties over the reduction of an essential part for an important government order. This training room has a number of machines which could be used for the manufacture of the part. Without in any way increasing the speed of their operations the learners working on the particular machines were put on that special part. They turned it out with practically no spoilage - a much better ratio both of speed and accuracy than the factory department could show-and saved the day for the delivery. Yet the work was merely made a part of the training room's instruction. It is the experience of all manufacturers who have such training that their turnover is greatly reduced. Those who cannot make good in the factory are found out in the training. Those who can make good are conditioned to the need and go into the factory understanding the rules and discipline, ready to produce satisfactory manufactured material. It is a common occurence to obtain a statement from a factory having training that their turnover has been reduced one-half since the training room was introduced.

Well-trained labor is more truly versatile because it has a broader vision of its opportunity and a better understanding of its duties. It is more secure in its employment inasmuch as proper training gives labor an understanding of all the possibili- 
ties of the machine upon which employed, and workmen thus equipped are certainly much more profitable to an employer because so much more adaptable. If wage levels are to be maintained, high living costs lowered, and foreign markets met and dominated, it can only be by improving the national average output. One of the most essential elements in that improvement must be a deliberate building up of sound industrial training. 